\title{
Desafios para a implementação do Controle de Convencionalidade pela Administração Pública no Brasil*
}

\author{
Challenges for the implementation of conventionality control by \\ the administrative authorities in Brazil
}

Gabriel Perlingeiro ${ }^{1}$

\begin{abstract}
RESUMO
O artigo se debruça sobre o exercício do controle de convencionalidade pela Administração Pública, nos moldes previstos na jurisprudência da Corte Interamericana de Direitos Humanos, a fim de que ele passe a representar, no Brasil, mecanismo efetivo de implementação de padrões interamericanos de proteção de direitos. Para tanto, a partir de uma pesquisa documental e doutrinária, examina, em primeiro lugar, o problema do fundamento dos direitos humanos, demonstrando a importância que a incorporação desses direitos no ordenamento jurídico representa para a sua plena efetividade. Em seguida, descreve o advento da Convenção Americana de Direitos Humanos, bem como em que medida o Brasil se sujeita às suas disposições. Prossegue com a apresentação da doutrina do controle interno de convencionalidade segundo a jurisprudência da Corte Interamericana de Direitos Humanos, com foco no seu entendimento de que o dever de controle alcança as autoridades administrativas nacionais. Por fim, identifica quais garantias institucionais seriam necessárias para o incremento do exercício dessa nova função pelas autoridades administrativas brasileiras. Conclui que, para a implementação dos padrões latino-americanos de direitos humanos no seio da Administração Pública brasileira, mediante o exercício do dever de controle de convencionalidade, impõe-se revisitar o seu modelo institucional.
\end{abstract}

\section{PALAVRAS-CHAVE:}

Direitos humanos; Sistema Interamericano de Direitos Humanos; controle de convencionalidade; Administração Pública.

\section{ABSTRACT:}

The paper focuses on the exercise of conventionality control by the administrative authorities, in the manner provided for in the jurisprudence of the Inter-American Court of Human Rights, so that it starts to represent, in Brazil, an effective mechanism for the implementation of interAmerican standards for the protection of rights. Therefore, based on documental and doctrinal research, it examines, first, the problem of the foundation of human rights, demonstrating the importance that the incorporation of these rights in the legal system represents for its full effectiveness. It then describes the advent of the American Convention on Human Rights, as well as the extent to which Brazil is subject to its provisions. It proceeds with the presentation

$\triangle$ Gabriel Ribeiro Perlingeiro Mendes

grperlingeiro@gmail.com

* Este artigo deriva parcialmente da dissertação de mestrado do autor, defendida no bojo do Programa de PósGraduação em Justiça Administrativa da Faculdade de Direito da Universidade Federal Fluminense

${ }^{1}$ Mestre em Justiça Administrativa pela Universidade Federal Fluminense (UFF). Procurador do Estado de São Paulo. 
of the doctrine of internal control of conventionality, according to the jurisprudence of the InterAmerican Court of Human Rights, focusing on its understanding that the duty of control reaches the national administrative authorities. Finally, it identifies which institutional guarantees would be necessary to increase the exercise of this new role by the Brazilian administrative authorities. It concludes that, for the implementation of Latin American human rights standards within the Brazilian Public Administration, through the exercise of the duty to control conventionality, it is necessary to revisit its institutional model.

\section{KEYWORDS:}

Human rights; Inter-American Human Rights System; conventionality control; administrative authorities.

\section{INTRODUÇÃO}

A Corte Interamericana de Direitos Humanos (Corte I.D.H.) reconheceu, em 2010, no caso Cabrera García y Montiel Flores Vs. México, que o controle de convencionalidade deve ser difuso e alcançar as autoridades administrativas nacionais. Nesse contexto, desde então, deve ser intensificada a pesquisa acerca do controle de convencionalidade dentro da Administração Pública, a fim de que ele passe a representar, no Brasil, mecanismo efetivo de implementação de padrões interamericanos de proteção de direitos.

Eis o impasse que se propõe enfrentar. De um lado, há consenso doutrinário e jurisprudencial de que a Administração deve estar pautada na juridicidade (e não mais legalidade estrita) e sob a primazia dos direitos fundamentais, o que vai ao encontro da jurisprudência da Corte I.D.H., de que compete, não apenas aos juízes, mas principalmente às autoridades administrativas, o controle de convencionalidade. De outro lado, o modelo brasileiro de Administração, com autoridades desprovidas de prerrogativas para uma atuação independente, é incompatível com regras que consagram tais proposições, que, na prática, limitam-se a uma retórica.

Esse cenário é fértil para a ineficácia de direitos nos moldes previstos pelo Sistema Interamericano de Direitos Humanos. Impõe-se, assim, a busca por medidas que implementem, no seio da Administração, a recepção, aplicação e interpretação de normas convencionais. 
Para alcançar esse objetivo, o texto, a partir de pesquisa doutrinária e documental, se desdobra em quatro partes. Em primeiro lugar, examina o problema do fundamento dos direitos humanos, demonstrando a importância que a incorporação desses direitos no ordenamento jurídico representa para a sua plena efetividade. Em seguida, descreve o advento da Convenção Americana de Direitos Humanos, bem como em que medida o Brasil se sujeita às suas disposições. Prossegue com a apresentação da doutrina do controle interno de convencionalidade segundo a jurisprudência da Corte Interamericana de Direitos Humanos, com foco no seu entendimento de que o dever de controle alcança as autoridades administrativas nacionais. Por fim, identifica quais garantias institucionais seriam necessárias para o incremento do exercício dessa nova função pelas autoridades administrativas brasileiras.

\section{O PROBLEMA DO FUNDAMENTO DOS DIREITOS HUMANOS}

Entender a importância do mecanismo do controle de convencionalidade passa necessariamente pela questão da fundamentação dos direitos humanos, que remonta, por sua vez, ao problema da sua justificação racional. Trata-se de debate sobre a natureza e validade universal dessa categoria de direitos que se pretende aplicável a todos os Estados que integram uma sociedade de povos politicamente justa. ${ }^{2}$

Eusébio Fernández aponta que, ao longo da história, pôde-se observar três tipos de justificação racional: (i) a jusnaturalista; (ii) a historicista; (iii) a ética. ${ }^{3}$

A fundamentação jusnaturalista parte de duas crenças: a distinção entre direito natural e direito positivo; e a superioridade do direito natural sobre o direito positivo. Segundo os adeptos dessa fundamentação, os direitos humanos são direitos naturais, ou seja, direitos derivados de um ordenamento universal decorrentes da própria natureza humana, anteriores e superiores ao direito positivo. ${ }^{4}$

\footnotetext{
${ }^{2}$ BARRETTO, Vicente de Paulo. O fetiche dos direitos humanos e outros temas. Rio de Janeiro: Lumen Juris, 2010. p. 255.

${ }^{3}$ FERNÁNDEZ, Eusébio. Teoria de la justicia y derechos humanos. 3 ed. Madrid: Editorial Debate, 1991. p. 84.

${ }^{4}$ Ibid., p. 86-87.
} 
Fernández elenca os entendimentos mais relevantes dessa vertente: (i) a origem dos direitos humanos, aqui entendidos como direitos naturais, não está no direito positivo, mas sim em uma ordem jurídica distinta: a ordem jurídica natural, inerente ao ser humano, anterior e superior às legislações escritas; (ii) a ordem jurídica natural é expressão da natureza humana, comum e universal para todos os homens, pouco importando as disposições do direito positivo a que a pessoa está submetida; (iii) os direitos humanos existem e são objeto de titularidade independentemente do seu reconhecimento no direito positivo. ${ }^{5}$

A crítica a essa orientação reside, essencialmente, na vagueza do conteúdo da natureza humana. Todas as teorias jusnaturalistas têm em comum o fato de que o conceito de natureza é aquele entendido segundo os valores prévios de cada corrente de pensamento, o que contraria a universalidade pregada pelos jusnaturalistas. ${ }^{6}$ Ademais, a independência das condições históricas própria dos direitos naturais não encontra respaldo na empiria. Nota-se que o conteúdo, o número e a importância dos direitos humanos se alteraram ao longo da história, de acordo com as necessidades, interesses, desejos e transformações técnicas de uma determinada época: o direito humano ao meio ambiente saudável seria impensável no séc. XVIII.

Por outro lado, de acordo com a fundamentação historicista, os direitos humanos são variáveis e relativos a cada contexto histórico que o homem se insere. Assim, "no lugar de direitos naturais, universais e absolutos, se fala em direitos históricos, variáveis e relativos; e no lugar de direitos anteriores e superiores, se fala de direitos de origem social, enquanto resultado da evolução da sociedade". ${ }^{7}$ Nesse passo, "os direitos humanos derivam de um processo de autoconsciência, baseado, não na natureza humana, mas sim nas necessidades humanas e nas possíveis formas de satisfazê-las dentro de uma sociedade". ${ }^{8}$ Logo, o conteúdo dos direitos humanos se subordina a valores de uma sociedade em concreto e às suas demandas específicas em um determinado tempo. Seriam verdadeiros direitos históricos.

Essa é a posição de Norberto Bobbio, para quem

os direitos do homem, por mais fundamentais que sejam, são direito históricos, ou seja, nascidos em certas circunstâncias, caracterizadas por lutas em defesa de novas liberdades contra velhos poderes, e nascidos de modo gradual, não todos de uma vez e nem de uma vez por todas. (...) Essas exigências nascem somente quando nascem

\footnotetext{
${ }^{5}$ Ibid., p. 93-94.

${ }^{6}$ Ibid., p. 96-97.

${ }^{7}$ Ibid., p. 101.

${ }^{8}$ Ibid., p. 101.
} 
determinados carecimentos. Novos carecimentos nascem em função da mudança das condições sociais e quando o desenvolvimento técnico permite satisfazê-los. ${ }^{9}$

A fundamentação ética ou axiológica, por sua vez, surge como reação ao excessivo relativismo da posição historicista. Se, por um lado, concorda que os direitos cívicos-políticos e os direitos econômicos-sociais são frutos de demandas do seu tempo, por outro, se opõe a relativização de direitos pessoais, como o direito à vida e à integridade física e moral, que figurariam como um "substrato permanente".

Essa teoria parte da premissa de que a origem e o fundamento desses direitos são prévios ao direito positivo. Assim, a função do direito positivo não é criar os direitos humanos, mas sim reconhecê-los, convertê-los em normas jurídicas e garanti-los também em âmbito jurídico, sem o que eles não terão plena efetividade. ${ }^{10}$ Contudo, o fundamento dos direitos humanos é ético, consistente em direitos morais, isto é,

exigências éticas e direitos que os seres humanos possuem pelo fato de serem homens, e, portanto, com igual direito ao seu reconhecimento, proteção e garantia por parte do Poder político e o direito positivo, independentemente de qualquer contingência histórica ou cultural, característica física ou intelectual, poder político ou classe social. $^{11}$

Vicente Barretto insere a ideia kantiana de dignidade da pessoa humana no centro da busca pelo núcleo moral universal dos direitos humanos, cujo conteúdo se desdobra em duas máximas: (i) não tratar a pessoa humana com simples meio e (ii) assegurar as necessidades vitais da pessoa humana. ${ }^{12}$ Enquanto a primeira deriva do imperativo categórico de Kant, de acordo com o qual a pessoa deve ser sempre um fim em si mesmo, a segunda assume que o homem é um ser com necessidades tangíveis, que precisam ser atendidas para retirá-lo do estado de degradação. ${ }^{13}$

Dessa forma, afirma o autor que

os direitos humanos referem-se, antes de tudo, a uma categoria de direitos que têm o caráter de abrigar e proteger a existência e o exercício das diferentes capacidades do

\footnotetext{
${ }^{9}$ BOBBIO, Norberto. A Era dos Direitos. 7a Triagem. Rio de Janeiro: Elsevier, 2004. p. 9-10.

${ }^{10}$ FERNÁNDEZ, Eusébio. Teoria de la justicia y derechos humanos. 3 ed. Madrid: Editorial Debate, 1991. p. 106.

${ }^{11}$ Ibid., p. 107.

12 BARRETTO, Vicente de Paulo. O fetiche dos direitos humanos e outros temas. Rio de Janeiro: Lumen Juris, 2010. p. 78.

${ }^{13}$ Ibid., p. 79.
} 
ser humano (que independem da cultura), que irão encontrar na ideia de dignidade da pessoa humana, o seu ponto convergente. ${ }^{14}$

Uma vez delimitados os valores morais universais como resposta a exigências imprescindíveis ao exercício da dignidade humana, a sua expressão em normas jurídicas revelase essencial para sua integração nas sociedades multiculturais, dando substância ao princípio da dignidade da pessoa humana. Logo,

não basta afirma-se que, por exemplo, a dignidade da pessoa humana é um valor, mas
para que ela se materialize nas relações sociais é necessário que ela se traduza em
normas. Essas normas é que irão objetivas a ideia de dignidade de pessoa humana que
deixa de ser afirmada como argumento retórico e passa a integrar através de normas
jurídicas específicas. ${ }^{15}$

Nessa linha, são direitos humanos aqueles que se referem a valores comuns e universais, fruto da razão humana, que se relacionam com a ideia de dignidade da pessoa humana e independem da vontade do legislador, sendo certo, contudo, que, para serem concretizados, devem ser incorporados ao ordenamento jurídico.

Assim, diferentemente das teorias jusnaturalistas, a visão ético-filosófica não se resume à mera identificação dos direitos humanos como direito naturais, independentemente de sua incorporação ao direito positivo, mas exige o seu reconhecimento e proteção pela ordem jurídica. Embora aceite a existência moral prévia dos direitos humanos, deixa claro que, sem uma norma jurídica de conduta, a sua existência não se completa.

Portanto, apenas com a estruturação de uma ordem jurídica voltada aos direitos humanos e com mecanismos efetivos para sua implementação, é possível alcançar o direito cosmopolita e a paz perpétua pregados por Kant.

\section{A CONVENÇÃO AMERICANA DE DIREITOS HUMANOS E A SUBMISSÃO DO BRASIL ÀS SUAS DISPOSIÇÕES}

No nosso continente, o principal documento jurídico positivo voltado à efetivação desses direitos morais é a Convenção Americana de Direitos Humanos (CADH). Ela foi aprovada na Conferência de São José da Costa Rica, em 22 de novembro de 1969, reproduzindo,

\footnotetext{
${ }^{14}$ Ibid., p. 266.

${ }^{15}$ Ibid., p. 268.
} 
em grande parte, as declarações de direitos constantes do Pacto Internacional de Direitos Civil e Políticos de $1966 .^{16}$

Tendo promulgado a CADH em 1992, pelo Decreto ${ }^{\circ}$ 678, de 6 de novembro daquele ano, e reconhecido a competência contenciosa da Corte Interamericana de Direitos Humanos (Corte I.D.H.) em 1998, pelo Decreto Legislativo $n^{\circ}$ 89, o Estado brasileiro se encontra completamente integrado ao Sistema Interamericano de Direitos Humanos. Por essa razão, deve obediência aos parâmetros de proteção dos direitos humanos fixados no corpus juris interamericano.

O direito internacional é resultado de manifestações de consentimento de Estados para se vincularem a tratados e criarem para si mesmos obrigações internacionais. Dessa forma, a exigência do seu cumprimento não viola a soberania estatal, sendo, ao contrário, decorrência desta última. Como afirma Piovesan, redefine-se a noção de soberania estatal absoluta, que passa incorporar em seu conceito compromissos e obrigações de alcance internacional no que diz respeito aos direitos humanos. ${ }^{17}$

Dito isso, a Convenção de Viena sobre Direito dos Tratados de 1969 (CVDT) elenca as três regras que regem a necessidade de obediência aos tratados internacionais: (i) os Estados só se vinculam na medida do consentimento outorgado (art. 2.1. b)); (ii) o convencionado deve ser fielmente observado (art. 26); (iii) apenas os Estados Partes devem obediência às obrigações do tratado (art. 34, 35 e 36). Em resumo, diz-se que os países signatários dos documentos internacionais devem cumprir as obrigações deles emanadas.

Nesse cenário, é certo que costumes e normas internas não podem servir de justificativa para a desobediência dos tratados celebrados (art. 26 da CVDT). Na hipótese de incompatibilidade entre o direito doméstico e as convenções internacionais, ou se modifica as disposições do ordenamento interno, ou se incorre em responsabilidade internacional. Para esse efeito, o direito internacional sempre tem primazia sobre o direito interno, pouco importando o status normativo que os Estados Partes conferem aos tratados internacionais em âmbito doméstico.

\footnotetext{
${ }^{16}$ COMPARATO, Fabio Konder. A afirmação histórica dos direitos humanos. São Paulo: Saraiva, 2001. p. 363. ${ }^{17}$ PIOVESAN, Flávia. Direitos humanos e o direito constitucional internacional. 15 ed. São Paulo: Saraiva, 2015. p. 190.
} 
No Brasil, os tratados possuem três hierarquias diferentes. ${ }^{18}$ Aqueles aprovados em cada Casa do Congresso Nacional, em dois turnos, por três quintos dos votos dos respectivos membros, são equivalentes às emendas constitucionais (art. $5^{\circ}, \S 3^{\circ}$, da $\mathrm{CF}$ ); tratados internacionais de direitos humanos aprovados pelo procedimento ordinário (art. 47 da $\mathrm{CF}$ ) ostentam natureza supralegal, situando-se abaixo da Constituição e acima das leis ordinárias $\left(\mathrm{CF} \text {, art. } 5^{\circ}, \S 2^{\circ}\right)^{19}$; as convenções, por sua vez, que cuidam de outros temas ingressam no ordenamento com força de lei ordinária.

Nota-se, assim, que a posição atual do ordenamento brasileiro em relação à matéria é, por si só, afrontosa aos princípios da CVDT, dando margem à responsabilização internacional do Brasil no caso de incongruência entre as normas internas e as normas internacionais. Isso porque, sob a ótica do direito internacional, os tratados são sempre vistos como normas materialmente supraconstitucionais.

Contudo, há outras formas de abertura do direito interno ao direito internacional que transcendem a discussão sobre hierarquia normativa e permitem aos Estados orientar-se pelos parâmetros internacionais mesmo se, em âmbito interno, os tratados sejam formalmente relegados à estatura de pouco prestígio.

Em primeiro lugar, apontam-se as "cláusulas de interpretação", que autorizam ao operador interpretar os direitos fundamentais constitucionais à luz dos tratados de direitos humanos, promovendo verdadeira "interpretação conforme". Parte da premissa que o ordenamento jurídico é um sistema e, como tal, deve ser dotado de unidade e harmonia. ${ }^{20}$

Em segundo lugar, observam-se as "cláusulas de direitos implícitos", declarando que os direitos expressos na Constituição não excluem outros reconhecidos em tratados internacionais. ${ }^{21}$ Trata-se do fundamento do denominado "bloco de constitucionalidade"; que

\footnotetext{
${ }^{18}$ MORAES, Guilherme Peña de. Curso de Direito Constitucional. 5 ed. São Paulo: Editora Atlas, 2013. p. 2629.

${ }^{19}$ BRASIL. STF. RE 466.343-1/SP, Tribunal Pleno. Relator Ministro Cezar Peluso. Brasília, 03 de dezembro de 2008. DJE 104 de 05 jun. 2009.

${ }^{20}$ DULITZKY, Ariel E. La aplicación de los tratados sobre derechos humanos por los tribunales locales: um estúdio comparado. In: ABREGÚ, Martin; COURTIS, Christian. La aplicación de los tratados sobre derechos humanos por los tribunales locales. Buenos Aires: Editores del Puerto/CELS, 1997. p. 41.

${ }^{21}$ Ibid, p. 42-43.
} 
confere status constitucional não apenas às normas formalmente constitucionais, mas também às normas materialmente constitucionais. ${ }^{22}$

No Brasil, essas aberturas são viabilizadas pelo art. $5^{\circ}, \S 2^{\circ}$, da CF:

$\S 2^{\circ}$ Os direitos e garantias expressos nesta Constituição não excluem outros decorrentes do regime e dos princípios por ela adotados, ou dos tratados internacionais em que a República Federativa do Brasil seja parte.

Nesse contexto, considerando se tratar de norma internacional de direitos humanos, a $\mathrm{CADH}$, por força do entendimento consolidado no STF, goza formalmente de status supralegal no direito doméstico. ${ }^{23}$ Isso se dá sem prejuízo de que normas constitucionais sejam objeto de interpretação conforme os padrões interamericanos de direitos humanos; na busca da sua tutela mais efetiva, tal como previsto na cláusula de abertura da Constituição Federal e imposto pelo sistema de responsabilização internacional.

Assentada a obrigação incondicional do Brasil de observar a CADH e verificada a posição de supremacia normativa do corpus juris interamericano no direito doméstico, não há dúvidas de que, na implementação de direitos, as autoridades públicas devem se guiar pelo marco jurídico do Sistema Interamericano de Direitos Humanos.

\section{O CONTROLE INTERNO DE CONVENCIONALIDADE NO SISTEMA INTERAMERICANO DE DIREITOS HUMANOS}

Aplicar os parâmetros interamericanos sobre direitos humanos, ainda que em contradição com a norma nacional, encerra verdadeiro controle de convencionalidade.

\footnotetext{
${ }^{22}$ MERA, Manuel Góngora. La difusion del bloque de constitucionalidad en la jurisprudencia latinoamericana y su potencial en la contrucción del ius constitutionale commune latinoamericano. In: VON BOGDANDY, Armin; FIX-FERRO, Héctor; ANTONIAZZI, Mariela Morales. Ius constitutionale commune en America Latina. Rasgos, Potencialidades y Desafios. México, D.F.: IIJ/UNAM e Instituto Max Planck de derecho Público Comparado y Derecho Internacional, 2017. p. 301-302.

${ }^{23}$ BRASIL. STF. RE 466.343-1/SP, Tribunal Pleno. Relator Ministro Cezar Peluso. Brasília, 03 de dezembro de 2008. DJE 104 de 05 jun. 2009.
} 
Fazem parte das obrigações dos Estados, enquanto signatários da $\mathrm{CADH}$, respeitar e garantir o exercício dos direitos previstos na Convenção (1.1. da CADH) e manter a harmonia entre o corpus juris interamericano e o direito doméstico (art. 2 da CADH). Segundo a Corte I.D.H., a necessidade de adequação do direito interno implica duas medidas: (i) supressão de normas e práticas que violam a Convenção; ${ }^{24}$ (ii) edição de normas e promoção de práticas destinadas à efetivação da Convenção. ${ }^{25}$

Dessas obrigações, a Corte extraiu, pela primeira vez em 2006, no caso Almonacid Arellano y otros vs. Chile, o conceito de "controle de convencionalidade", definindo-o como instrumento voltado à efetivação dos parâmetros interamericanos de direitos humanos no plano interno, em que os Estados Partes se comprometem a incorporar as normas necessárias a sua proteção mediante a aplicação das normas convencionais pelas autoridades internas. ${ }^{26}$

Sérgio García Ramirez conceitua o mecanismo como "controle interno de convencionalidade", a fim de disitingui-lo do "controle próprio, original ou externo de convencionalidade, que incumbe apenas ao tribunal supranacional provocado a exercer a confrontação entre atos domésticos e as disposições convencionais". ${ }^{27}$

Em decisões posteriores, a Corte desenvolveu o instituto, consolidando jurisprudência sobre vários aspectos referentes ao controle interno de convencionalidade exercido no âmbito do Sistema Americano de Direitos Humanos.

\subsection{Parâmetros do controle de convencionalidade}

O posicionamento da Corte é o de que o texto da CADH revela-se tão somente como parâmetro mínimo do controle de convencionalidade. Isso porque a interpretação da Corte I.D.H. sobre a CADH é igualmente vinculante aos Estados Partes, devendo ser observada no controle de convencionalidade. Supõe-se que, ao consentir com a CADH, os Estados delegaram

\footnotetext{
${ }^{24}$ CORTE IDH. Caso Suárez Rosero Vs. Ecuador. São José, 12 de novembro de 1997. Série C No. 35 , § 98.

${ }^{25}$ CORTE IDH. Caso Castillo Petruzzi y otros Vs. Perú. São José, 30 de maio de 1999. Série C No. 52, § 20.

${ }^{26}$ CORTE IDH. Caso López Álvarez Vs. Honduras. São José, 1 de fevereiro de 2006. Série C No. 141.

${ }^{27}$ RAMÍREZ, Sergio García. El control judicial interno de convencionalidad. IUS Revista del Instituto de Ciencias Jurídicas de Puebla, México, ano V, n. 28, p.126, jul./dez. 2011.
} 
à Corte, enquanto órgão judicial do Sistema, a competência interpretativa defintiva do tratado, seja no exercício da sua competência contenciosa ou consultiva. ${ }^{28}$

Incluem também como parâmetro do controle os demais documentos internacionais integrantes do corpus juris interamericano e as respectivas interpretações da Corte sobre seu alcance $^{29}$, notadamente a Convenção Interamericana sobre o Desaparecimento Forçado de Pessoas; a Convenção Interamericana contra o Racismo; o Protocolo a Convenção Americana de Direitos Humanos relativos à Abolição da Pena de Morte; a Convenção Interamericana para Prevenir, Sancionar e Erradicar a Violência conta a Mulher; o Protocolo Adicional a Convenção Americana de Direitos Humanos em matéria de Direitos Econômicos, Sociais e Culturais (Protocolo de San Salvador); a Convenção Interamericana para Prevenir e Sancionar a Tortura; a Convenção Interamericana para a Eliminação de Todas as Formas de Discriminação Contra as Pessoas de Deficiência; a Discriminação Racial e Formas Conexas de Intolerância; a Convenção Interamericana contra toda Forma de Discriminação e Intolerância; e a Convenção Interamericana sobre a Proteção dos Direitos Humanos dos Idosos.

\subsection{Objetos do controle de convencionalidade}

De acordo com a jurisprudência interamericana, é o mais amplo possível o objeto de controle, incluindo desde a Constituição dos Estados Partes até leis ordinária, normas infralegais e precedentes vinculantes. ${ }^{30}$

Assim, toda regra doméstica está submetida ao controle de convencionalidade, inclusive a própria Constituição nacional. Nesse passo, Nestor Sagües esclarece que

A Convenção assume, assim, agrade ou não essa conclusão, condição de supraconstitucionalidade. Por isso, como no caso "A última tentação de Cristo", por exemplo, a Corte Interamericana de Direitos Humanos determinou ao Chile modificar uma cláusula da Constituição local contrária à Convenção". ${ }^{31}$

\footnotetext{
28 SAGÜÉS, Néstor. Obligaciones internacionales y control de convencionalidad. Revista Estudios Constitucionales, Talca, v. 8, n. 1, p. 125-126, 2010.

${ }^{29}$ CORTE IDH. Caso Gudiel Álvarez y otros ("Diario Militar") Vs. Guatemala. São José, 20 novembro de 2012. Série C No. 253, § 330.

${ }^{30}$ CORTE IDH. Caso Atala Riffo y Niñas Vs. Chile. São José, 24 de fevereiro de 2012. Série C No. 239, $\S \S 80,91$ e 284.

31 SAGÜÉS, Néstor. Obligaciones internacionales y control de convencionalidad. Revista Estudios Constitucionales, Talca, v. 8, núm. 1, p. 124, 2010.
} 


\section{3 Órgãos habilitados a realizarem o controle de convencionalidade}

O referido controle tinha inicialmente como destinatários todos os juízes nacionais, porém mais tarde ficou assentado que, no âmbito de suas respectivas competências, todas as autoridades e todos os órgãos de um Estado Parte da Convenção têm a obrigação de exercer um controle de convencionalidade. ${ }^{32}$ Hodiernamente, é pacífico, na Corte I.D.H., que todos os órgãos e Poderes do Estado Parte estão obrigados a cumprir as obrigações internacionais decorrentes do Sistema Interamericano de Direitos Humanos, e não apenas o Poder Judiciário.

Disso decorre que, na visão da Corte, autoridades administrativas responsáveis por implementar direitos, ainda que não jurisdicionais, devem observar a conformidade das normas e práticas internas com o corpus juris interamericano no exercício das suas funções.

Não é outra a posição de Silvia Guzmán, para quem o controle de convencionalidade deve fazer parte da agenda diária da Administração Pública, pois

Todas as autoridades estatais dos diferentes Poderes e hierarquias podem comprometer a responsabilidade internacional de um Estado Parte na Convenção Interamericana de Direitos Humanos, se não ajustam o exercício das suas funções às previsões desse instrumento. (...) Dessa perspectiva, o exercício do controle de convencionalidade por parte das autoridades nacionais tem uma importante função preventiva de violação de direitos humanos. ${ }^{33}$

A mesma lógica se aplica ao Poder Legislativo, cujos membros estão vinculados ao parâmetros do Sistema Interamericano de Direitos Humanos na sua atividade legiferante. Vale dizer, ficam impossibilitados de editar normas contrárias às disposições da Convenção e obrigados a aprovar normas destinadas à promoção das suas garantias. ${ }^{34}$

\subsection{Características procedimentais do controle de convencionalidade}

\footnotetext{
32 CORTE IDH. Caso Cabrera García y Montiel Flores Vs. México. São José, 26 de novembro de 2010. Série C No. 220, $\S 21,225$ e 233; CORTE IDH. Caso de personas dominicanas y haitianas expulsadas Vs. República Dominicana. São José, 28 de agosto de 2014. § 471.

${ }^{33}$ SERRANO, Silva. El control de convencionalidad en la jurisprudencia de la Corte Interamericana de Derechos Humanos. México, D.F.: CNDH, 2013. p. 15-16.

${ }^{34}$ CORTE IDH. Caso Tarazona Arrieta y otros Vs. Perú. São José, 15 de outubro de 2014. Série C no $286, \S 153$.
} 
Muito embora a Corte não imponha um modelo estanque para o controle de convencionalidade, elenca algumas características essenciais ao processo de controle.

Em primeiro lugar, este é realizado ex officio. Assim, a aplicação direta da norma internacional independe da provocação do interessado, cabendo à autoridade competente fazer incidir a Convenção no caso concreto. ${ }^{35}$

Em segundo lugar, o controle é de caráter imediato. É dizer, o cumprimento da Convenção não pode se condicionar a futuras mudanças no direito interno. Na hipótese de incompatibilidade, aplicam-se os parâmetros internacionais e ignora-se a norma doméstica. ${ }^{36}$

Em terceiro lugar, a Corte reconhece que devem ser respeitadas as regras nacionais de competência e processo. Sendo assim, as autoridades procedem ao controle de convencionalidade dentro das suas funções e de acordo com o procedimento delimitado no direito interno.

Nesse ponto, a Corte I.D.H. admite diferentes níveis de intensidade do controle de convencionalidade, a depender da competência conferida ao agente:

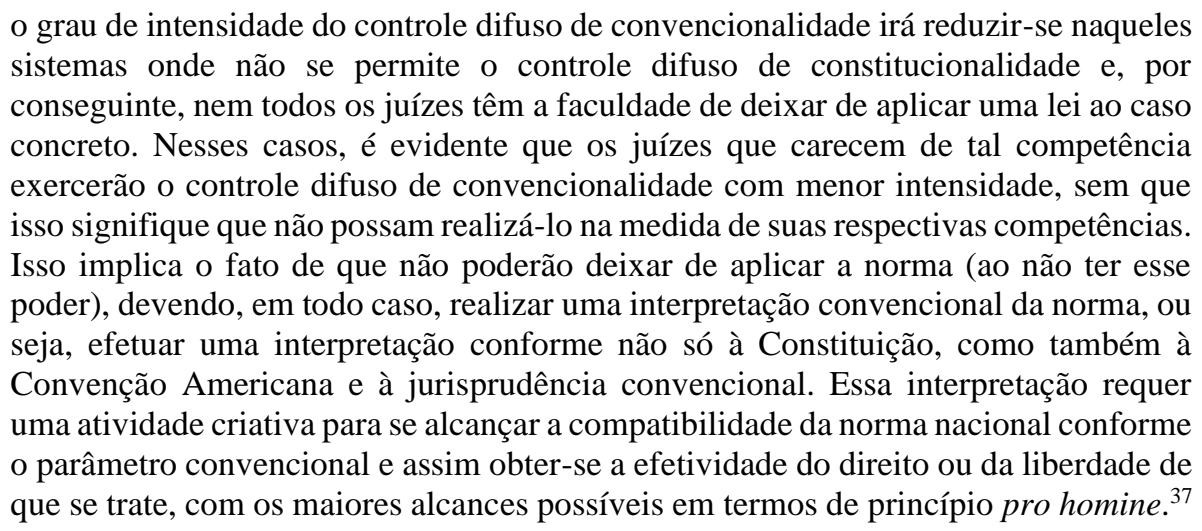

Havendo absoluta incompatibilidade,

onde não exista interpretação convencional possível, se o juiz carece de faculdades para deixar de aplicar a norma, irá se limitar a assinalar a anti-convencionalidade da mesma ou, nesse caso, a semear a dúvida da inconvencionalidade diante de outros

\footnotetext{
${ }^{35}$ CORTE IDH. Caso Liakat Ali Alibux Vs. Surinam. São José, 30 de janeiro de 2014. Série C No. $276, \S 124$.

${ }^{36}$ CORTE IDH. Caso Cabrera García y Montiel Flores Vs. México. São José, 26 de novembro de 2010. Série C No. $220, \S 233$.

${ }^{37}$ CORTE IDH. La sentencia de supervisión del cumplimento en el caso Gelman Vs. Uruguay. São José, 20 de março de 2013. § 37.
} 
órgãos jurisdicionais competentes dentro do mesmo sistema jurídico nacional que podem exercer o controle de convencionalidade com maior intensidade. Assim, os órgãos jurisdicionais de revisão terão que exercer dito controle e deixar de aplicar a norma ou declarar a sua invalidade por ser anti-convencional. ${ }^{38}$

Sendo assim, na hipótese de a autoridade não possuir competência para deixar de aplicar uma lei interna, tal como ocorre com as autoridades administrativas ou com os juízes ordinários em sistemas de controle concentrado de constitucionalidade, o controle de convencionalidade será de menor intensidade, resumindo-se à "interpretação conforme" ou à instauração do incidente de anti-convencionalidade.

A noção de “interpretação conforme", por sua vez, está fundamentada no art. 29 da $\mathrm{CADH}$, de modo que

\begin{abstract}
nenhuma disposição da presente Convenção pode ser interpretada no sentido de: a) permitir a algum dos Estados parte, grupo ou pessoa, suprimir o gozo e exercício dos direitos e liberdades reconhecidos na Convenção ou limitá-los em maior medida que nela prevista; b) limitar o gozo e exercício de qualquer direito ou liberdade que possa estar reconhecido de acordo com as leis de qualquer dos Estados parte ou de acordo com outra Convenção em que seja parte um dos referidos Estados; c) excluir outros direitos e garantias que são inerentes ao ser humano ou que se derivem da forma democrática representativa de governo; e d) excluir ou limitar o efeito que possam produzir a Declaração Americana de Direitos e Deveres Humanos e outros atos internacionais da mesma natureza.
\end{abstract}

Dessa forma, se uma lei nacional autoriza duas ou três interpretações, o operador deve preferir aquela que se alinhe à CADH e eliminar as interpretações que resultem em violação à Convenção. Trata-se de uma vertente construtiva do controle de convencionalidade. ${ }^{39}$

Em quarto lugar, destaca-se a complementariedade entre o controle de convencionalidade e o controle de constitucionalidade. Dessa forma, quando diante de uma norma ou prática inconstitucional, o intérprete deve apurar não só a sua conformidade com a Constituição Nacional, mas também com a CADH. ${ }^{40}$

\footnotetext{
${ }^{38}$ Ibid., $\$ 39$.

39 SAGÜÉS, Néstor. Obligaciones internacionales y control de convencionalidad. Revista Estudios Constitucionales, Talca, v. 8, n. 1, p. 130 e 132, 2010.

${ }^{40}$ CORTE IDH. La sentencia de supervisión del cumplimento en el caso Gelman Vs. Uruguay. São José, 20 de março de 2013. $\$ 88$.
} 


\section{O CONTROLE DE CONVENCIONALIDADE PELA ADMINISTRAÇÃO PÚBLICA E OS DESAFIOS PARA A SUA IMPLEMENTAÇÃO NO BRASIL}

A doutrina do controle de convencionalidade pela Administração Pública, amplamente reconhecida pela Corte I.D.H., como visto acima, se apresenta como peça fundamental para a concretização do dever das autoridades administrativas de efetivarem os direitos humanos nos moldes previstos pelo Sistema Interamericano de Direitos Humanos.

Com efeito, não basta que a compatibilidade entre o direito nacional, os princípios da OEA e a jurisprudência da Corte I.D.H. se limite a declarações de direitos e deveres. Ao contrário, o dever das autoridades administrativas de proteger direitos humanos fundamentais impõe que haja mecanismos institucionais que permitam que elas implementem diretamente os padrões internacionais de tutela jurídica, ainda que dissonantes das normas nacionais.

O princípio da legalidade estrita, do ponto de vista da supremacia da lei (que se opõe ao princípio da reserva da lei), é um capítulo ultrapassado na literatura e jurisprudência do Brasil. Reconhece-se que as autoridades devem orientar-se pela juridicidade, isto é, pelo império dos direitos fundamentais. ${ }^{41}$ É esse novo paradigma que também serve de pano de fundo para a doutrina da Corte I.D.H. sobre controle de convencionalidade pela Administração Pública. Com efeito, trata-se de um grande avanço:

\footnotetext{
o controle de convencionalidade exercido pela jurisdição contencioso-administrativa amplia, ostensivamente, o parâmetro de legitimidade ao qual as condutas administrativas devem, substancialmente, adequar-se, o que provoca uma reorganização das fontes do direito administrativo, ao incorporar o bloco de convencionalidade como fator de contraste, e permite também vislumbrar um direito administrativo comum. ${ }^{42}$
}

No entanto, desafiar a literalidade da lei não é prática usual dos agentes administrativos brasileiros. Isso fica evidente ao se observar a natureza da grande maioria dos conflitos

\footnotetext{
${ }^{41}$ Ver WOLF, Hans J.; BACHOF, Otto; STOBER, Rolf. Direito Administrativo. v. 1. Tradução Antônio F. de Souza. Lisboa: Fundação Calouste Gulbenkian, 2006. p. 427; BINENBOJM, Gustavo. Uma teoria do direito administrativo: direitos fundamentais, democracia e constitucionalização. 2 ed. Rio de Janeiro: Renovar, 2008; MOREIRA NETO, Diogo de Figueiredo. Curso de Direito Administrativo. 16 ed. Rio de Janeiro: Forense, 2014; CASTRO, Carlos Roberto Siqueira. A Constituição aberta e os direitos fundamentais: Ensaios sobre o constitucionalismo pós-moderno e comunitário. Rio de Janeiro: Forense, 2010; BARROSO, Luís Roberto. Interpretação e aplicação da Constituição. 7 ed. Rio de Janeiro: Saraiva, 2012.

42 JINESTA, Ernesto. Control de convencionalidad difuso ejercido por la jurisdicción constitucional. Revista Peruana de Derecho Público, Lima, ano 16, n. 31, p. 50, 2015.
} 
administrativos que chegam ao Judiciário: questões que envolvem interpretação teleológica das normas, não raro, capazes de levar ao esvaziamento normativo.

Apontam-se duas razões pelas quais tal controle ainda não foi efetivamente implementado no Brasil:

\begin{abstract}
A uma, porque persiste na cultura jurídica latino-americana uma relação de subordinação entre Administração Pública e Governo, a qual acarreta o desprezo pelo requisito da capacidade técnica, em favor das indicações meramente políticas na escolha de funcionários públicos para ocuparem cargos-chave nas tomadas de decisão. A duas, porque prevalece na mentalidade dos funcionários públicos o dogma de que devem maior compromisso à subordinação hierárquica do que à legalidade, e muitos temem que, desafiando interpretações literais da lei, em favor de direitos fundamentais, possam ser acusados por desvio de conduta funcional. ${ }^{43}$
\end{abstract}

Nota-se que há uma cultura que prefere a subordinação hierárquica, em detrimento da liberdade decisória no plano da Administração Pública, que, nesse contexto, guia-se mais por critérios políticos do que critérios técnicos.

Isso se deve ao próprio modelo de Administração Pública no Brasil. Aqui, não obstante a ampla previsão constitucional do devido processo (art. $5^{\circ}, \mathrm{LIV}$, da CF), as autoridades administrativas não são dotadas de garantias de independência e qualificação técnica, ficando inviabilizada a prestação de um processo administrativo justo. Vale dizer, o ordenamento nacional, via de regra, não confere ao agente decisório as condições institucionais necessárias para uma atuação livre e justa, pois sujeitam-nos ao princípio da subordinação hierárquica e não lhes exigem conhecimento jurídico técnico suficiente.

Este é o cenário: se, por um lado, os agentes devem obediência às orientações fixadas pelos seus superiores, por outro, estes são indicados politicamente, em nomeação de cargo em comissão. Nessa esteira, as decisões nunca decorrem de um devido processo, visto que, em última instância, se originam de autoridades despidas de conhecimento técnico e atreladas a interesses políticos, sem qualquer garantia.

Essa definição de independência converge com a que defende a Corte I.D.H., segundo a qual significa ser "autônomo em todas as ordens de seu desempenho jurisdicional, dotado das faculdades para resolver, sem ingerência de outros órgãos do Estado ou de qualquer outra

\footnotetext{
${ }^{43}$ PERLINGEIRO, Ricardo. Desafios contemporâneos da justiça administrativa na América Latina. Revista de Investigações constitucionais, Curitiba, v. 4, n. 1, p. 192, 2017.
} 
instância, as lides que lhe sejam submetidas" ${ }^{\text {44 }}$. Em suma, se a decisão do funcionário é motivada por razões outras que não a sua convicção técnica, ele é carente de independência. ${ }^{45}$

Paralelamente, a jurisprudência da Corte impõe que as autoridades administrativas responsáveis pelo controle de convencionalidade atendam condições destinadas a assegurar uma tomada de decisão não arbitrária ${ }^{46}$ e sob o manto do devido processo legal. ${ }^{47}$ Entende-se ainda que a adequada formação jurídica garante uma maior vontade jurídica para operar o controle.

Em matéria de direito de acesso à informação, reconhecendo a indispensabilidade do devido processo legal na função administrativa, a Assembleia Geral da OEA, na Lei Modelo Interamericana sobre Acesso à Informação Pública e a Guia para sua Implementação, previu expressamente que a satisfação efetiva do direito pressuporia a criação de um órgão administrativo autônomo, independente e especializado responsável por implementar a legislação internacional às pretensões de acesso à informação que lhe fossem encaminhadas. ${ }^{48}$

Sendo assim, eis o impasse quanto ao controle de convencionalidade pela Administração Pública brasileira. De um lado, há consenso na jurisprudência da Corte I.D.H. de que a Administração deve estar pautada na juridicidade (e não mais na legalidade estrita) e sob a primazia dos direitos humanos. Sendo assim, a Administração deve encontrar parâmetro de atuação não apenas no direito interno, mas, antes, no corpus juris interamericano. De outro lado, o modelo brasileiro de Administração, carente de uma atuação independente e qualificada, é incompatível com regras que consagrem tais proposições, que, na prática, limitam-se a uma retórica. Esse cenário é fértil para a inutilização do controle de convencionalidade e, em consequência, para a ineficácia dos direitos humanos fundamentais em âmbito administrativo.

O fato é que, historicamente, nunca integrou a cultura latino-americana uma jurisdição administrativa extrajudicial prévia fortalecida (primary jurisdiction), dotada de todos os atributos que revestem o devido processo legal. Isso porque, por tradição, sempre foi orientada

\footnotetext{
${ }^{44}$ CORTE IDH. Caso Palamara Iribame Vs. Chile. São José, 22 de novembro de 2005, § 9.

45 PERLINGEIRO, Ricardo. Desafios contemporâneos da justiça administrativa na América Latina. Revista de Investigações constitucionais, Curitiba, v. 4, n. 1, p. 193, 2017.

${ }^{46}$ CORTE IDH. Caso Claude Reyes y otros Vs. Chile. São José, 19 de setembro de 2006, Série C No. 151, § 119; Caso Barbani Duarte y Otros Vs. Uruguay. São José, 13 de outubro de 2011. Série C No. 234, § 119.

${ }^{47}$ CORTE IDH. Caso Claude-Reyes y otros vs. Chile. São José, 19 de setembro de 2006, § 118 e 119.

48 OEA. CIDH. Los órganos de supervisión del derecho de acceso a la información pública. Relatoria Especial para a Liberdade de Expressão, 2016. $§ 10$.
} 
pelo civil law, marcado pela ausência do due process na fase anterior à formação da decisão administrativa ${ }^{49}$ Com efeito, de acordo com a classificação de Michael Asimow, o modelo brasileiro, acompanhando a tendência dos países da Europa continental, possui um "processo de elaboração da decisão inicial e de reconsideração relativamente desestruturado", caracterizado por um julgamento inquisitorial. ${ }^{50}$

Assim, não existe no Brasil um processo administrativo regido por autoridades independentes. Na prática, a cláusula do due process só ganha envergadura na fase judicial da jurisdição administrativa. Não é outra a razão pela qual o controle jurisdicional sobre o ato administrativo é amplo, a fim de suprir o presumido déficit processual da fase anterior. ${ }^{51}$

Ao revés, o direito administrativo nos regimes jurídicos vinculados ao common law mais se ajustam às condições necessárias a um controle efetivo de convencionalidade dentro da Administração Pública. Tal estrutura caracteriza-se pela aplicação da cláusula do devido processo em todas as etapas do processo administrativo, mediante a existência de agências administrativas quase-judiciais dotadas de independência e capacidade técnica, cujas decisões, por essa razão, gozam de intensa deferência judicial. ${ }^{52}$ Michael Asimow registra que, nos Estados Unidos, o Judiciário, quando provocado a controlar ato administrativo, tende a confiar mais na decisão tomada na fase extrajudicial, pois envolve uma "audiência de julgamento adversarial perante um Hearing Office relativamente independente". ${ }^{53}$

É nesse sistema que devem se inspirar as modificações do corpo administrativo brasileiro a fim de incorporar-lhes os atributos para efetivarem a juridicidade plena e não apenas a legalidade estrita, habilitando-as, assim, a exercerem um controle efetivo de convencionalidade, tal como proposto na jurisprudência da Corte I.D.H.

\footnotetext{
${ }^{49}$ PERLINGEIRO, Ricardo. A historical perspective on administrative jurisdiction in Latin America. Continental European Tradition vs. US Influence. British Journal of American Legal Studies - BJALS, Birmingham, v. 5, n.1, p. 261, 2016.

50 ASIMOW, Michael. Cinco modelos de adjudicação administrativa (Justiça Administrativa). Revista de Investigações Constitucionais, Curitiba, v. 4, n. 1, p. 148, jan./abr. 2017.

${ }^{51}$ Ibid., p. 148.

52 CANE, Peter. Administrative tribunals and adjudication. Oxford: Hart Publishing, 2010. p. 57.

53 ASIMOW, Michael. Cinco modelos de adjudicação administrativa (Justiça Administrativa). Revista de Investigações Constitucionais, Curitiba, v. 4, n. 1, p. 141, jan./abr. 2017.
} 


\section{CONCLUSÃO}

De acordo com a sua fundamentação ética ou axiológica, os direitos humanos consistem em direitos morais, isto é, exigências éticas imanentes à condição humana e que preexistem ao direito positivo. Contudo, essa corrente não deixa de reconhecer a importância da sua incorporação ao ordenamento jurídico. Os direitos humanos apenas terão plena efetividade na medida em que forem convertidos e garantidos também em âmbito normativo. Daí decorre a relevância do estudo de mecanismos jurídicos destinados à efetiva implementação desses direitos.

Nesse passo, enquanto Estado Parte da CADH, o Brasil assumiu a obrigação internacional de respeitar e garantir o exercício dos direitos previstos na Convenção (1.1 da $\mathrm{CADH}$ ) e de manter a harmonia com o corpus juris interamericano (art. 2 da CADH). Assim, na implementação dos direitos humanos, o país deve se orientar pelos parâmetros de proteção fixados pelo marco jurídico do Sistema Interamericano de Direitos Humanos, ainda que eventualmente dissonantes do direito nacional.

No caso Cabrera García y Montiel Flores Vs. México, a Corte I.D.H. estabeleceu entendimento, consolidado em precedentes posteriores, de que esse dever alcança todos os órgãos do Estado Parte, sendo certo que compete também às autoridades administrativas recepcionar, aplicar e interpretar o direito convencional.

O dever de controle de convencionalidade atribuído às autoridades administrativas assume especial relevância no Brasil, onde prevalece, na doutrina e jurisprudência, que as autoridades devem orientar-se pela juridicidade, isto é, pelo império dos direitos fundamentais.

Ocorre, contudo, que o modelo de estrutura administrativa brasileira não acomoda as condições necessárias à efetiva adoção do controle de convencionalidade pela Administração Pública, declaradas pela própria Corte I.D.H. e pela Assembleia Geral da OEA. Vale dizer, na sua função executiva, as autoridades não se sujeitam a um verdadeiro devido processo legal, pois não são dotadas de garantias de independência tampouco de qualificação técnica. 
Disso conclui-se que, para a implementação dos padrões latino-americanos de direitos humanos no seio da Administração Pública brasileira, mediante o exercício do dever de controle de convencionalidade, impõe-se revisitar o seu modelo institucional. Essa reforma deve se inspirar nos regimes jurídicos vinculados ao common law, caracterizados pela aplicação da cláusula do devido processo em todas as etapas do processo administrativo, mediante a existência de agências administrativas quase-judiciais dotadas de independência e capacidade técnica.

Só assim as autoridades administrativas brasileiras serão capazes de exercer um controle de convencionalidade nos moldes previstos pela jurisprudência da Corte I.D.H., passando a representar mecanismo efetivo de garantia dos padrões interamericanos de proteção de direitos.

\section{REFERÊNCIAS}

ASIMOW, Michael. Cinco modelos de adjudicação administrativa (Justiça Administrativa). Revista de Investigações Constitucionais, Curitiba, v. 4, n. 1, p. 129-165, jan./abr. 2017.

BARRETTO, Vicente de Paulo. Ofetiche dos direitos humanos e outros temas. Rio de Janeiro: Lumen Juris, 2010.

BARROSO, Luís Roberto. Interpretação e aplicação da Constituição. 7 ed. Rio de Janeiro: Saraiva, 2012.

BINENBOJM, Gustavo. Uma teoria do direito administrativo: direitos fundamentais, democracia e constitucionalização. 2 ed. Rio de Janeiro: Renovar, 2008.

BOBBIO, Norberto. A Era dos Direitos. 7aTriagem. Rio de Janeiro: Elsevier, 2004.

BRASIL. Supremo Tribunal Federal. RE 466.343-1/SP, Tribunal Pleno. Relator Ministro Cezar Peluso. Brasília, 03 de dezembro de 2008. DJE 104 de 05 jun. 2009.

CANE, Peter. Administrative tribunals and adjudication. Oxford: Hart Publishing, 2010.

CASTRO, Carlos Roberto Siqueira. A Constituição aberta e os direitos fundamentais: Ensaios sobre o constitucionalismo pós-moderno e comunitário. Rio de Janeiro: Forense, 2010.

COMPARATO, Fabio Konder. A afirmação histórica dos direitos humanos. São Paulo Saraiva, 2001.

CORTE IDH. Caso Atala Riffo y Niñas Vs. Chile. São José, 24 de fevereiro de 2012. Série C No. 239. 

No. 234.

Caso Barbani Duarte y Otros Vs. Uruguay. São José, 13 de outubro de 2011. Série C . Caso Cabrera García y Montiel Flores Vs. México. São José, 26 de novembro de 2010. Série C No. 220.

Caso Castillo Petruzzi y otros Vs. Perú. São José, 30 de maio de 1999. Serie C No. 52.

. Caso Claude Reyes y otros Vs. Chile. São José, 19 de setembro de 2006. Série C No. 151.

. Caso de personas dominicanas y haitianas expulsadas Vs. República Dominicana. São José, 28 de agosto de 2014.

. Caso Gudiel Álvarez y otros ("Diario Militar") Vs. Guatemala. São José, 20 novembro de 2012. Série C No. 253.

. Caso Liakat Ali Alibux Vs. Surinam. São José, 30 de janeiro de 2014. Série C No. 276.

. Caso López Álvarez Vs. Honduras. São José, 1 de fevereiro de 2006. Série C No. 141.

. Caso Palamara Iribame Vs. Chile. São José, 22 de novembro de 2005.

. Caso Suárez Rosero Vs. Ecuador. São José, 12 de novembro de 1997. Série C No. 35.

286.

Caso Tarazona Arrieta y otros Vs. Perú. São José, 15 de outubro de 2014. Série C No.

La sentencia de supervisión del cumplimento en el caso Gelman Vs. Uruguay. São José, 20 de março de 2013.

DULITZKY, Ariel E. La aplicación de los tratados sobre derechos humanos por los tribunales locales: um estúdio comparado. In: ABREGÚ, Martin; COURTIS, Christian. La aplicación de los tratados sobre derechos humanos por los tribunales locales. Buenos Aires: Editores del Puerto/CELS, 1997. p. 33-74.

FERNÁNDEZ, Eusébio. Teoria de la justicia y derechos humanos. 3 ed. Madrid: Editorial Debate, 1991.

JINESTA, Ernesto. Control de convencionalidad difuso ejercido por la jurisdicción constitucional. Revista Peruana de Derecho Público, Lima, ano 16, n. 31, p.47-57, 2015.

MAC-GREGOR, Eduardo Ferrer. The constitutionalization of international law in Latin American conventionality control: The new doctrine of the Corte Interamericana de Direitos Humanos. American Society of International Law - AJIL Unbound, Washington, v. 109, p. 9399, 2015.

MERA, Manuel Góngora. La difusion del bloque de constitucionalidad en la jurisprudencia latinoamericana y su potencial en la contrucción del ius constitutionale commune 
latinoamericano. In: VON BOGDANDY, Armin; FIX-FERRO, Héctor; ANTONIAZZI, Mariela Morales. Ius constitutionale commune en America Latina. Rasgos, Potencialidades y Desafios. México, D.F.: IIJ/UNAM e Instituto Max Planck de derecho Público Comparado y Derecho Internacional, 2017. p. 301-327.

MORAES, Guilherme Peña de. Curso de Direito Constitucional. 5 ed. São Paulo: Editora Atlas, 2013.

MOREIRA NETO, Diogo de Figueiredo. Curso de Direito Administrativo. 16 ed. Rio de Janeiro: Forense, 2014.

OEA. CIDH. Los órganos de supervisión del derecho de acceso a la información pública. Relatoria Especial para a Liberdade de Expressão, 2016.

PERLINGEIRO, Ricardo. A historical perspective on administrative jurisdiction in Latin America. Continental European Tradition vs. US Influence. British Journal of American Legal Studies - BJALS, Birmingham, v. 5, n.1, p. 241-289, 2016.

. Desafios contemporâneos da justiça administrativa na América Latina. Revista de Investigações constitucionais, Curitiba, v. 4, n. 1, p. 167-205, jan./abr. 2017.

PIOVESAN, Flávia. Direitos humanos e o direito constitucional internacional. 15 ed. São Paulo: Saraiva, 2015.

RAMÍREZ, Sergio García. El control judicial interno de convencionalidad. IUS Revista del Instituto de Ciencias Jurídicas de Puebla, México, ano V, n. 28, p.123-159, jul/dez de 2011.

SAGÜÉS, Néstor. Obligaciones internacionales y control de convencionalidad. Revista Estudios Constitucionales, Talca, v. 8, n. 1, p. 117-135, 2010.

SERRANO, Silva. El control de convencionalidad en la jurisprudencia de la Corte Interamericana de Derechos Humanos. México, D.F.: CNDH, 2013.

WOLF, Hans J.; BACHOF, Otto; STOBER, Rolf. Direito Administrativo. v. 1. Tradução Antônio F. de Souza. Lisboa: Fundação Calouste Gulbenkian, 2006.

Data de Submissão: 01/07/2020

Data de Aceite: 05/08/2020 